\title{
LXIV. Remarks on Mr. Barton's reply, respecting the inflection of light
}

\author{
Rev. B. Powell M.A. F.R.S.
}

To cite this article: Rev. B. Powell M.A. F.R.S. (1833) LXIV. Remarks on Mr. Barton's reply, respecting the inflection of light, Philosophical Magazine Series 3, 3:18, 412-417, DOI: 10.1080/14786443308648218

To link to this article: http://dx.doi.org/10.1080/14786443308648218

册 Published online: 01 Jun 2009.

Submit your article to this journal $\lceil\pi$

Џ Article views: 2

Q View related articles $₫$ 
412 The Rev. B. Powell's Remarks on Mr. Barton's Reply,

and stifled, i.e. dispersed, by the agency of the colouring matter which acts the part of the air in Mr. Wheatstone's experiment, and self-neutralized by the opposition of its subdivided portions as above explained.

Slough, October 19, 1833.

LXIV. Remarks on Mr. Barton's Reply, respecting the Inflection of Light. By the Rev. B. Powel, M.A. F.R.S. Savilian Professor of Geometry, Oxford.

\section{To the Editors of the Philosophical Magazine and Journal.}

Gentlemen,

DID not see your Number for September last, containing $1 \mathrm{Mr}$. Barton's reply to my former paper, till very lately, and now hasten to send a few brief observations, which that reply seems to call for, and which I trust you will favour me by inserting in your Journal.

In the first place allow me to say that the courteous tenour of Mr. Barton's paper assures me that he will regard my present communication with the same candour as he has done the former; and in that spirit of candour I will proceed at once to the essential questions at issue.

The important and conclusive experiment is that in which the aperture has straight parallel edges. Here Fresnel's formula applies directly, and accords most exactly with the phænomena. This is evident both from what I have stated (Lond. and Edinb. Phil. Mag., vol. ii. p. 431-2), and from the exact experiments of Professor Airy, described in my postscript ( $1 b$. p. 433). On this part of the question $l$ do not perceive that Mr. Barton alleges any result of his own of an opposite kind. The only difficulty is about an experiment of Newton's. (Optics, book iii. obs. 5.) Now this experiment, as I before observed, is involved in considerable ambiguity. I am not aware whether Mr. Barton bas succeeded in reproducing it with all the concomitant circumstances as described by Newton, viz. the "long trains of light" which he speaks of, \&c. These are as essential to be explained as the appearance of a dark space in the centre. I have repeatedly tried to verify this experiment, but entirely without success; and I am much inclined to believe that there were some circumstances in the conditions of the case of which we are not fully informed. It is surely, then, most imperatively incumbent on us to ascertain carefully all the conditions, before we allege it in opposition to the united testimony of all other experiments.

But with respect not only to this, but also to the other ex 
periments recorded by Newton in the place referred to, it is certainly most unfair and injurious to his memory to quote them without bearing in mind his strong and peculiar remark respecting them (at the end of observation 11.): "When I made the foregoing observations, I designed to repeat most of them with more care and exactness, and to make some new ones for determining the manner how the rays of light are bent in their passage by bodies for making the fringes of colours with the dark lines between them. But I was then interrupted, and cannot now think of taking these things into further consideration; and since $I$ have not tinished this part of my design, I shall conclude with proposing only some queries, in order to a further search to be made by others."

And again, in the "Advertisement" prefixed to the book: "The subject of the third book I have also left imperfect, not having tried all the experiments which $I$ intended when I was about these matters, nor repeated some of those which I did try until I had satisfied myself about all their circumstances. To communicate what I have tried, and leave the rest to others for further inquiry, is all my design in publishing these papers."

These remarks of the illustrious author will speak for themselves; and it is evident he would be the last to urge his confessedly imperfect trials in opposition to decisive results. But even here I have, I think, sufficiently shown in my former paper, how very small his inaccuracies were; and the only case in which any real contradiction appears, is one, as I observed above, in which it is almost certain that we do not accurately know all the conditions.

Next, with regard to curvilinear edges, I would observe that no comparison can be fairly drawn between any experiments with straight edges and those with curved. Mr. Barton, in adopting the latter, has chosen a method which in calculation would involve extreme complexity, and it is a case to which the formula in question does not apply. In the case of the rectilinear parallel edges, an important simplification is afforded, as we have only to calculate the effects in one plane, viz. in that perpendicular to the length of the slit and to the plane of the edges. Whereas with curred edges we must combine with this the effect in the plane of the length of the aperture. To make a fair application, then, of the theory, we ought to follow out the calculation, and modify the formulæ, so as to include this case.

This, it will be readily acknowledged, by any one acquainted with the nature of the formula, will be a difficult investigation; nevertheless it is essential to go through it before we 


\section{The Rev. B. Powell's Remarks on Mr. Barton's Reply,}

can pronounce even the result as observed by $\mathbf{M r}$. Barton to be at variance roith the theory. And without entering into any calculation, it is obvious, on the mere consideration just referred to, (viz. the influence of the portions of light entering at the wider parts of the aperture in the direction of its length,) that the character of that part of the image corresponding to the narrowest part of the aperture will not be simply determined by the case of a rectilinear slit of the same width. Unfortunately I am not aware that any such investigation has been given, even in the case of inclined rectilinear edges.

Now with regard to my experiments: I have tried edges of extremely small curvature, and have never been able to find a black isolated central spot with bright fringes continuing at the sides, which is what $\mathbf{l}$ understand $\mathrm{Mr}$. Barton to have seen. When, on the approach of the edges, the centre became dull or dark, at the same moment all appearance of bright bands at the sides ceased, these bands breaking off into hyperbolic branches.

On this part of my description Mr. Barton makes the remark (present vol. p. 172), that from the byperbolic form of the curves it follows that a line at right angles to the length of the aperture must at some part cut through bright bands, having a central dark part between them. This, I must observe, really does not follow, because the hyperbolic branches extend but a very little way before they are quite lost and confounded in the shadow on either side; and the dark part in the centre of the figure stretches across, as it were, forming a junction between the shadows from each side. It is altogether very obscure, and ill-defined, and shades off so gradually into the bright central part above and below that it is quite impossible to say where it terminates. But supposing a dark centre to be really established, then I conceive the case to stand briefly thus:Mr. Barton has brought forward a new experimental case,and the science of theoretical optics is under great obligations to him for doing so,-a case to which neither the undulatory nor any other theory (except, I suppose, his own,) has as yet been applied. It remains to be seen how they may apply; and this case will form a further test of the powers of either theory WHEN FORMULE APPLYING TO THIS CASE SHALL HAVE BEEN INVESTIGATED.

In regard to my use of the expression " the coalescing of the shadows," I will only observe, that I did not employ it as a supplementary correction to the formula. It was suggested only in the case to which (as already observed,) the formula does not apply. It is, however, obviously included in the formula of Fresnel when the edges are parallel, as appears 
from the calculated numbers given in my former paper, where, with a very narrow aperture, the centre, though a point of relative brightness compared with other points in the same horizontal line, is yet a point of relative darkness compared with greater breadths of aperture. I am of course quite aware that, strictly speaking, the expression is incorrect, and though, perhaps, it may not inaptly facilitate the primary apprehension of the phænomenon, yet it undoubtedly involves a theory, and would therefore be better avoided. The idea that each edge carried with it its own fringes, which, as the two edges approached, crossed and overlapped, and thus gave rise to the bands actually observed, was the theory conceived by Biot in his analysis of the phænomenon. Fresnel's formula resolves the whole into an expression for the brightness of the light at points measured on a screen in a line at right angles to the length of the slit.

As to Mr. Barton's estimate of the comparative accuracy of the experiments of Newton, Biot and Fresnel, every reader will form his own judgement from the careful consideration of all the circumstances which ought to be taken into account. With respect to Biot's experiments, I see nothing to alter the conclusion at which I before arrived, by showing the probable amount of error which would bring the results into accordance; and $I$ apprehend that in most cases of this nature the presumption would be in favour of the later experimenters, without any real disparagement of the earlier. With respect to Newton's results there is one circumstance to be remarked which, I believe, escaped me when writing my former paper. The particular experiment of Newton in question is that of the inclined knife-edges. The formula with which it is compared is that of Fresnel for parallel edges. This, as I have above observed, is a most essential difference; and thus, whether the error lies with me or with Mr. Barton, the whole computation, from first to last, is altogether nugatory.

The difficulty which Mr. Barton has now more fully stated respecting the origin of the rays, does not appear to me to require more than a careful reference to what is laid down in the best treatises for its elucidation. The effect of waves propagated through a narrow aperture is ably explained either in Professor Airy's tract (art. 27), or in Sir J. Herschel's treatise on Light (art. 607. 628)*. But the author's view of the subject seems to be suggested as introductory to the original theory which he proposes; and it appears to me that it would be a far better course if, instead of encumbering

* Encyc. Metr., and Div, vol. ii. 


\section{Rev. B. Powell's Remarks on Mr. Barton's Reply.}

his views with extraneous considerations, he would give the scientific world a perspicuous and systematic development of them, so as fairly to contrast the explanation of the facts which his theory affords with that resulting from the other theories.

Perhaps it may not be altogether uninteresting to the reader to see at one view how the rival theories at present apply. I subjoin, therefore, a synoptic sketch, which I believe to be perfectly impartial; indeed, 1 have given every advantage to the corpuscular theory. It would be interesting if Mr. Barton would add a third column, giving a similar view of his own theory.

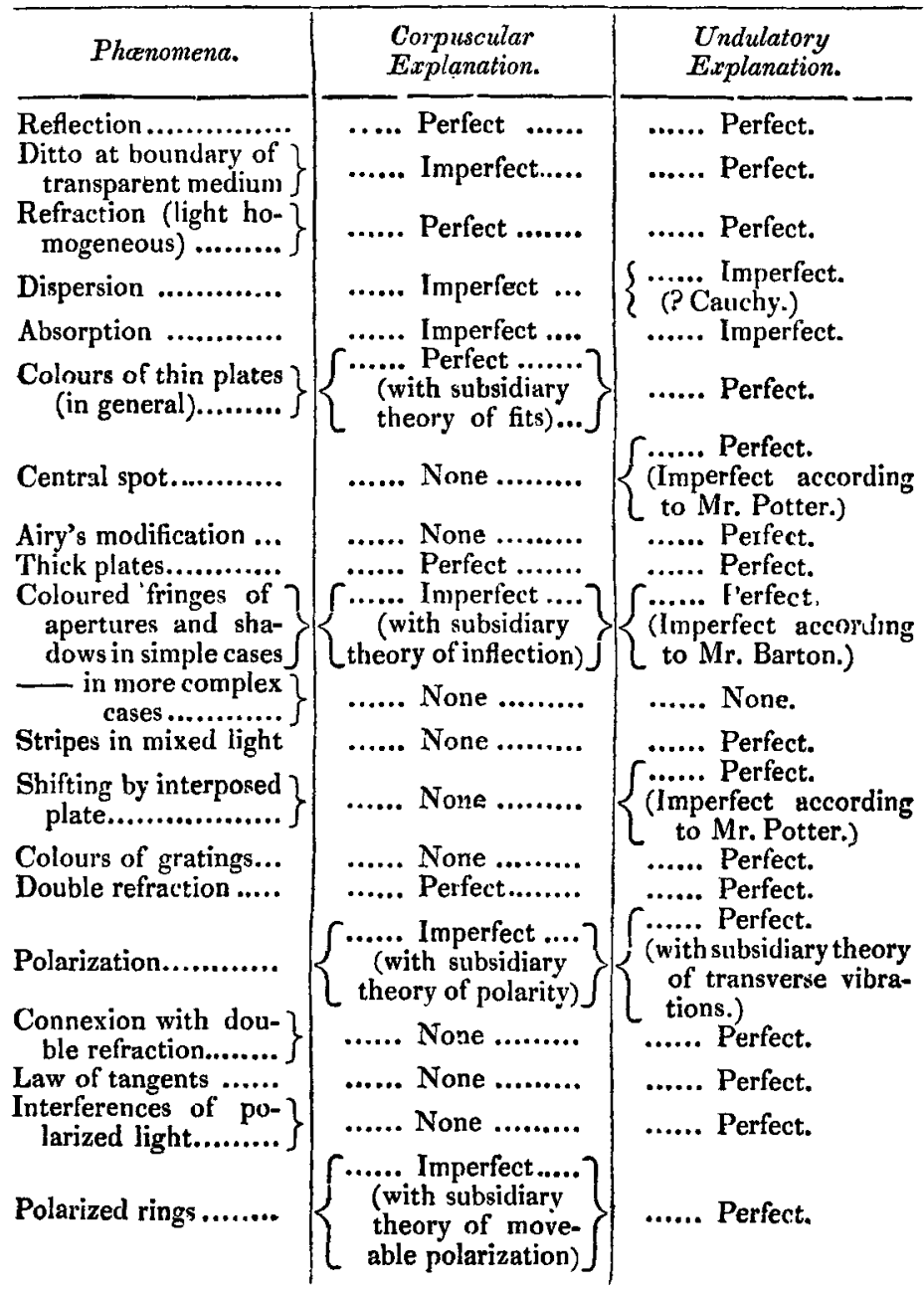




\begin{tabular}{|c|c|c|}
\hline I'hanomena. & $\begin{array}{l}\text { Corpuscular } \\
\text { Explanation. }\end{array}$ & $\begin{array}{l}\text { Undulatory } \\
\text { Explanation. }\end{array}$ \\
\hline $\left.\begin{array}{c}\text { Circular and elliptic } \\
\text { polarization : } \\
\text { at internal reflection }\end{array}\right\}$ & ...... None ......... & ...... Imperfect. \\
\hline at metallic surfaces & $\left\{\begin{array}{c}\ldots \ldots . \text { None ......... } \\
\text { (? SirD. Brewster) }\end{array}\right\}$ & ...... None. \\
\hline $\begin{array}{l}\text { Conical refraction.... } \\
\text { Oxford, Nov. 1, } 1833 .\end{array}$ & ...... None.......... & ...... Perfect. \\
\hline
\end{tabular}

LXV. On Mr. Murphy's Proof of the Existence of a real or imaginary Root for any proposed Equation.

To the Editors of the Philosophical Magazine and Journal. Gentlemen,

THE demonstration which appears in the Number of your Magazine for March 1833, by Mr. Murphy, does not seem to me to be conclusive.

For $\mathbf{P}$ is a function of $p$ and $q$ : as also is $\mathbf{Q}$ : now a value being assigned to $p$, a value is found for $q$, which makes $Q=0$ : and the value of $P$ in (1) depends upon these assigned values of $p$ and $q$.

Again: in the second substitution, for $p$ is put $p+h$. $\cos \frac{\pi}{n}$ the first part of this being the value above given to $p:$ a value is then found for $q+h \cdot \sin \frac{\pi}{n}$, and therefore for $q$, which makes $\mathrm{Q}=0$ : but this value does not necessarily appear to be the same value as before obtained for $q$, and therefore the value of $\mathrm{P}$ (which is a function of $p$ and $q$ ) in (2) is not the same as the value in (1).

J. HENRY.

Nov. 1, 1833.

LXVI. Observations on the Rise and Fall of Water in some Wells in Cornwall, with bricf Notices of other Matters bearing on the Phanomena of Springs; in a Letter to Sir Charles Lemon, Bart. M.P.F.R.S. By W.J. Henwood, F.G.S. Lond. and Paris, Hon. M. Y.P.S.* Sir,

A T Dr. Buckland's desire, and with the assistance of genA tlemen in various parts of Cornwall, I have endeavoured to follow up for one year the measurements first instituted in this country by Mr. Blandt, and which I have now the honour to present to your notice.

* Communicated by Sir Charles Lemon.

+ Phil. Mag. and Annals, vol. xi. p. 88.

Third Series. Vol. 3. No. 18. Dec. 1833. 